\title{
Do CSR Perceptions Influence Work Outcomes in the Health Care Sector? The Mediating Role of Organizational Identification and Employee Attachment
}

\author{
Souad Hassanie $^{1, *(\mathbb{D}, \text { Georgiana Karadas }}{ }^{1} \mathbb{D}$ and Okechukwu Lawrence Emeagwali ${ }^{2}$ \\ 1 Business Administration, Faculty of Economics and Administrative Sciences, Cyprus International University, \\ Via Mersin 10, Nicosia 99010, Turkey; gkaradas@ciu.edu.tr \\ 2 Department of Business Management, Faculty of Business and Economics, Girne American University, \\ Via Mersin 10, Kyrenia 99320, Turkey; lawrenceemeaggwali@gau.edu.tr \\ * Correspondence: souadhassanie@gmail.com
}

check for updates

Citation: Hassanie, S.; Karadas, G.; Lawrence Emeagwali, O. Do CSR Perceptions Influence Work

Outcomes in the Health Care Sector? The Mediating Role of Organizational Identification and Employee Attachment. Sustainability 2021, 13, 9840. https://doi.org/10.3390/ su13179840

Academic Editor: Andrea Appolloni

Received: 15 August 2021

Accepted: 27 August 2021

Published: 1 September 2021

Publisher's Note: MDPI stays neutral with regard to jurisdictional claims in published maps and institutional affiliations.

Copyright: (c) 2021 by the authors. Licensee MDPI, Basel, Switzerland. This article is an open access article distributed under the terms and conditions of the Creative Commons Attribution (CC BY) license (https:/ / creativecommons.org/licenses/by/ $4.0 /)$.

\begin{abstract}
A limited number of studies have emphasized the importance of corporate social responsibility (CSR) implementation in the health care sector. Based on social exchange theory and social identity theory, this paper examines the relationships between employees' CSR perceptions, employee attachment, organizational identification, corporate reputation, employee organization relationship, and extra-role performance utilizing structural equation modeling. Data were obtained from Lebanese health care workers in private hospitals in two questionnaires. The results indicate that CSR perceptions positively affect employee attachment and organizational identification. Moreover, employees' CSR perceptions positively affect work outcomes directly and indirectly via employee attachment. On the other hand, although organizational identification has a negative but significant relationship with employee organization relationships, it does not significantly influence corporate reputation and extra-role performance. Examining the two intervening variables that link CSR to work outcomes provides theoretical and practical implications. Contributions to health care management literature, as well as future research recommendations, are also presented.
\end{abstract}

Keywords: corporate social responsibility; organizational identification; employee attachment; work outcomes; health care

\section{Introduction}

Recent emerging diseases, diverse technological innovations and fierce competition are challenges facing the service industry, especially the health care sector, which are leading to a surge in corporate social responsibility (CSR) implementation. To enhance stakeholder social, environmental, and economic status while improving competitiveness and performance, researchers assessed the impact of CSR on the service industries' performance. In Lebanon, a limited number of studies have investigated the impact of CSR on the health care sector. Those that have, recommended a future assessment on the impact of health care workers' (HCWs) CSR perceptions on work outcomes [1,2]. Although CSR impact was interpreted from the employee perspective, many researchers (who investigated the micro-foundations of CSR) argued that these perceptions are insufficient [3]. Research indicates that CSR has a significant impact on employees' attitudes and behaviors related to identification [4], organizational citizenship behavior (OCB) [5], and attachment [6], which improve corporate reputation (CoRe) [7], trigger employees' extra role performance (ERP) [8], and maintain a high-quality employee-organization relationship (EOR) [9]. As a result, researchers called for urgent research due to the importance that CSR has on employee attitudes and work outcomes. This study develops a model that examines organizational identification (OI) and employee attachment (EA) as mediators on the effect of CSR on CoRe, EOR, and ERP. The proposed relationships are underpinned 
by social exchange theory (SET) and social identity theory (SIT), representing a gateway that regulates employees' behaviors according to the goal pursued in a given workplace with data being collected by HCWs in Lebanon in a two-wave survey.

Several empirical studies were conducted to determine the impact of CSR initiatives on work outcomes from a stakeholders' (including employees) perspective [3-8]. Employees are considered a fundamental group of stakeholders, able to transform CSR initiatives implemented by an organization into valuable work outcomes [4]. Therefore, employee CSR perceptions shape the community's opinion toward organizations [3]. Furthermore, valuable work outcomes can be enhanced and fostered as organizations implement CSR activities that promote the well-being and welfare of all stakeholders, including employees [4]. This study intends to determine the extent to which employees understand their organizations' CSR initiatives and how employees' CSR perceptions influence work outcomes.

The current study adapts Turker's (2009) CSR dimensions related to the environment, customers, society, government, and employees. The CSR dimensions proposed by Turker (2009) comprise all dimensions presented by Carroll (1991), including all legal, ethical, and discretionary obligations within and beyond an organization. In particular, if an organization implements CSR initiatives effectively, this would significantly influence employees' CSR perceptions and, consequently, enhance work outcomes (4).

This study provides the following contributions to the literature. Firstly, CSR in the Middle East (ME) does not reflect the same frame of analysis as in Western countries. Studies examined the impact of CSR on various industries in ME and Lebanon [10,11]. A current literature review indicates that several countries in ME suffer from institutional gaps [10], so some encourage CSR, while others demonstrate irresponsible actions due to governmental and religious restrictions [11]. Similarly, Amos (2018) indicated that CSR research is primarily conducted in developed countries rather than developing countries [12]. It is thus important to examine the relationship between CSR and employees' outcomes to clarify how CSR initiatives stimulate beneficial work outcomes in Lebanon.

Secondly, CSR initiatives influence employees' behaviors and attitudes. For instance, evidence indicates that CSR initiatives enhance employees' performance and identification [4]. When organizations care about employees' comfort, security, and social concerns, EA is enhanced [6]. On the one hand, researchers argued that the impact of CSR on employee identification is insufficient and recommended studying the relationship between these two constructs $[13,14]$. Likewise, assessing the level of EA among HCWs indicates that EA was highest among physicians and lowest among nurses and paramedics [15]. Exploring variations in OI and EA levels among nurses, physicians, and other healthcare providers, including laboratory technologists and radiology technicians, is needed.

Third, stakeholders evaluate the signals they perceive from their firms' CSR, especially when their social interest outweighs the firms' self-interest [7]. Researchers did not investigate the underlying mechanisms that show how the firms' reputation is affected. They did recommend research to identify the antecedents and outcomes of CoRe from a bottom-line employees' perspective [16]. Recent studies examined the relationship between CSR and employees' commitment to their organization but failed to indicate how CSR activities influence EOR through OI [17]. Hence, evidence is needed to broaden our current knowledge. Many empirical papers investigated CSR impact on several organizational behaviors from the employees' perspective, satisfaction, and commitment [18]. However, few studies examined the nexus between CSR and employees' ERP; they recommended future research to investigate the underlying mechanism [18]. Hence, this study provides more understanding of employees' societal concerns and their underlying influences.

Finally, researchers examined various moderating and mediating constructs in the relationship between CSR and valuable employees' outcomes in order to clarify how firms being engaged in CSR initiatives can stimulate beneficial outcomes [19]. Recent researchers investigated the mediating role of either OI or EA separately in different contexts and cultures, and their results were consistent with one another $[6,9,20]$. However, simultaneous 
investigation of OI and EA as mediators between CSR and work outcomes from employees' perspectives would add to the literature.

\section{Theoretical Foundation}

The conceptual framework is underpinned by two social theories: SET and SIT. They are used extensively in empirical studies to address CSR activities on the micro-level of organization, particularly employees.

SET reflects the social interactions generating reciprocity of benefits and obligations between organizations and employees [21]. For instance, evidence indicates that organizations that care about the wellness of their employees obtain workers who reciprocate by developing high-quality relationships [22] and demonstrating ERP and OCB [23]. Therefore, socially responsible organizations that care for their employees' welfare motivate employee reciprocity in the form of OI [24], extra role behavior [25], high work performance, and organizational commitment [26].

Meanwhile, SIT reflects the extent to which employees identify with their organization and the degree to which they consider the success or failure of one's organization as their own [27]. Employees who identify with prestigious firms will feel distinctive and possess positive behavior in the workplace $[14,17,24,25]$. According to SIT, CSR initiatives enhance a positive perception of one's workplace [24]. When employees participate in activities consistent with their identities, they provide support for their organization, thus, maintaining its reputation [28].

\section{Hypotheses Development}

\subsection{CSR Relationship with Organizational Identification and Employee Attachment}

CSR is an important tool that helps hospitals understand the societal needs of their community, resulting in higher performance and a better social image [1]. OI, a specific form of social identification, refers to the extent of belonging to different social groups [27]. CSR activities can induce OI since employees identify with organizations sharing their same values as a resource to increase their self-esteem [29]. SET suggests that employees develop feelings of obligation and reciprocate what they receive in the form of OI. EA is the extent to which employees bond to their firm, transforming the workplace into a personal one [30], based on the ability of their organization to fulfill social obligations [21,31]. Through SIT, CSR creates synergy between employees and firms, enhancing the emotional link between the two $[27,29]$. In the health care industry, research indicates that HCWs exhibit different levels of attachment to their workplace [15].

Accordingly, in line with SET, SIT, and previous empirical studies, CSR would positively influence EA and OI, leading to the following hypothesis:

Hypothesis 1 (H1). Employees' CSR perceptions are positively associated with EA (a) and OI (b).

\subsection{CSR and Work Outcomes}

CoRe consists of the collective perceptions of various stakeholders regarding the firm's ability to enhance societal welfare [7]. Various stakeholders highly appreciate CSR programs oriented toward social and environmental concerns. Several studies investigated the relationship between CSR and CoRe, assessed their underlying mechanisms, and suggest that managers can run CoRe as they integrate social and ethical principles into their work processes [20]. Furthermore, CSR initiatives help firms send signals about reliability that builds a strong CoRe $[7,20]$.

EOR refers to a specific dimension of organization-public relationship management [32]. Hon and Grunig (1999) identified four components of this relationship: commitment, trust, satisfaction, and control mutuality. Empirical studies investigated the impact of CSR on this relationship, in general, and on EOR in specific, and their results have been consistent with one another, where CSR activities have a significant impact on EOR [9]. 
ERP is an individual-directed OCB, demonstrated by employees to enhance organizational effectiveness [8]. A literature review showed that CSR has a significant impact on ERP [33]. Employees who experience OI demonstrated discretionary behaviors as ERP [13]. Based on SET, firms implementing CSR activities nurture employees' desires to reciprocate in ERP, improving effectiveness, performance, job satisfaction, and interpersonal interactions.

It is expected that CSR would positively influence CoRe, EOR, and ERP, providing the following hypothesis:

Hypothesis 2 (H2). Employees' CSR perceptions positively influence CoRe (a), EOR (b), and ERP (c).

\subsection{Organizational Identification and Work Outcomes}

Empirical studies examined the impact of OI on employees' behaviors and indicated a positive impact on different work outcomes [8,22]. Based on SIT, and due to the synergy between employees' identities and their organizations, employees witness more satisfaction and higher OI [29]. Several papers determined the positive impact of OI on ERP and OCB $[13,14,29]$. Furthermore, employees who identify with their organizations help maintain their positive reputation [17]. Chen et al. (2019) argued that employees' positive perceptions of company activities would create positive relational outcomes, resulting in a valuable EOR.

Based on these examinations, it is expected that OI would positively influence CoRe, EOR, and ERP, leading to the following hypothesis:

Hypothesis 3 (H3). OI influences CoRe (a), EOR (b), and ERP (c).

\subsection{Employee Attachment and Work Outcomes}

Previous studies showed that EA has a positive impact on employee attitudes such as high satisfaction, low turnover rates [31,34,35], OCB [5,36], and comfort at work [37]. Similarly, Luke et al. (2020) showed that EA is highly correlated with beneficial organizational outcomes; hence, employees identify with their workplace and maintain their organizations' reputation [28]. Based on the above, EA positively influences CoRe, EOR, and ERP, leading to the following hypothesis:

Hypothesis 4 (H4). EA influences CoRe (a), EOR (b), and ERP (c).

\subsection{Organizational Identification and Employee Attachment as Mediators}

The mediating role of OI between CSR and work outcomes is outlined by various empirical studies and was explained using SIT and SET. Carmeli et al. (2007) used OI to mediate CSR and employee performance [38]. In a study conducted by Brammer et al. (2015), OI mediated the relationship between CSR and innovative work practices [39]; OI was used to mediate the relation between CSR and ERP [8], OCB for the environment [40], and employee desire to have a significant impact [24]. When employees' needs were satisfied, the organizations were considered attractive [26], and they tended to identify with their firms, showing a higher OI, and demonstrating different work outcomes [24]. Firms that integrate responsible programs into their processes trigger OI, enhancing CoRe [20], ERP [14,29], and EOR [9]. The following hypothesis is advanced:

Hypothesis 5 (H5). OI mediates the relationship between employees' CSR perceptions and CoRe (a), $\operatorname{EOR}(b)$, and $\operatorname{ERP}(c)$.

In previous studies, research indicated that EA mediated the relationship between employees' perceptions of CSR activities and corporate performance. Kim et al. (2017) proposed a conceptual model investigating the impact of employees' CSR perceptions 
on work outcomes mediated by EA and OCB. As employees' needs were satisfied, they developed positive perceptions toward their firm's CSR, influencing attachment, OCB, and beneficial work outcomes. CSR activities enhance employees' perceptions [40] and their attachment to the workplace [6]. Many empirical studies show the positive impact of EA on work outcomes such as OCB and ERP [5,34], commitment, satisfaction [36], and CoRe [17]. Thus, the following hypothesis was developed:

Hypothesis 6 (H6). EA mediates the relationship between employees' CSR perceptions and CoRe $(a), \operatorname{EOR}(b)$, and $\operatorname{ERP}(c)$.

\section{Materials and Methods}

\subsection{Sampling and Procedures}

This study collected data from HCWs who had direct contact with patients like nurses, physicians, laboratory technologists, and radiology technicians. Data were collected over two weeks in two waves. According to the Syndicate of Hospitals in Lebanon, most hospitals (133) are private, providing $88 \%$ of health care services. However, 54 hospitals out of 133 agreed to participate in this study.

Human resource (HR) managers coordinated the data collection process. Prone to selection bias, researchers requested the human resource manager to distribute the questionnaires to HCWs in different departments. The HR managers provided supervisors with survey packs relevant to the number of HCWs in their departments with a cover letter including information about anonymity and confidentiality. The cover page indicated there are no right or wrong answers [41]. The questionnaires were returned in sealed envelopes. Items related to CSR and respondents' profiles, including age, gender, marital status, level of education, number of children, and work tenure, were included in the Time 1 questionnaire. The Time 2 questionnaire was comprised of EOR, CoRe, and ERP items. Five hundred and eighty-two (582) questionnaires were returned out of six hundred and nineteen (619) questionnaires, constituting a 94\% response rate [42]. Questionnaires can be found in Supplementary Material.

\subsection{Measurement Items}

The study adapted Turker's (2009) scale to measure CSR dimensions [43]. There are 17 items in Turker's (2009) scale used to measure employees' perceptions regarding their hospital's responsible actions towards stakeholders, including the environment, customers, society, government, and employees. The items mainly reflect the extent to which employees value CSR initiatives that address stakeholder welfare. EA was measured using the Workplace Attachment Scale (WAS) [44]. WAS is a unidimensional construct consisting of seven items and validated by Rioux (2006). WPA measures the degree to which employees are attached to their workplace based on their CSR perceptions. A sixitem scale was used to measure the construct OI adapted from the Mael and Ashforth (1992) study. These items intend to determine the degree to which employees identify with their organizations in accordance with their CSR perceptions. Moreover, this paper adapted Eisenberger et al.'s (2010) scale, composed of eight items, to measure ERP [45]. The items investigate an employee's ability to provide constructive suggestions, share knowledge and skills, protect organizational interests, and encourage responses to CSR initiatives implemented by organizations. Items related to CSR, EA, OI, and ERP were measured using a five-point Likert scale ( $1=$ strongly disagree to $5=$ strongly agree).

To measure CoRe from an employee perspective, the study used a three-item scale from Lai et al., (2010) [46]. The questions reflect the accumulated perceptions of all stakeholders, including employees, regarding the organization's ability to meet employees' expectations. EOR was measured using the Hon and Grunig (1999) scale. EOR consists of four dimensions: control mutuality, trust, commitment, and satisfaction with five items each. Only four items are negatively worded. All items related to CoRe and EOR were measured using a seven-point Likert scale ( $1=$ strongly disagree to $7=$ strongly agree). 
Gender, age, educational degree, organizational tenure, marital status, and number of children were treated as control variables.

All items in the questionnaires were prepared based on the back-translation method. The original version of the questionnaire was prepared in English. Then, it was translated from English to Arabic by a professional translator and translated back to the English language by another professional translator. Respondents were instructed to fill the questionnaires in a private place and return them in sealed envelopes. The questionnaire was tested with pilot samples of $20 \mathrm{HCWs}$ to confirm the understandability of the items. As a result, no changes in the wording of the questions were deemed necessary.

\section{Results}

\subsection{Sample Characteristics}

The participants' demographic characteristics, including age, gender, educational level, organizational tenure, marital status, and the number of children, are shown in Table 1. The study sample of $582 \mathrm{HCWs}$ in Lebanon included (37.8\%) 236 males and $362(62.2 \%)$ females. Participants were between $28-47$ years of age $(60.5 \%)$ and married $(51.5 \%)$. Most respondents had 1 to 4 children (69.8\%), a university degree (80.1\%), and worked for $>5$ years $(82.4 \%)$ in their organizations.

Table 1. Descriptive profile of the respondents.

\begin{tabular}{|c|c|c|c|}
\hline Demographic Variables & Categories & Frequency $(n=582)$ & Percentage \\
\hline \multirow[t]{2}{*}{ Gender } & Male & 220 & 37.8 \\
\hline & Female & 362 & 62.2 \\
\hline \multirow[t]{5}{*}{ Age } & 18-27 years & 50 & 8.6 \\
\hline & $28-37$ years & 146 & 25.1 \\
\hline & $38-47$ years & 206 & 35.4 \\
\hline & $48-57$ years & 121 & 20.8 \\
\hline & 58 and over & 59 & 10.1 \\
\hline \multirow[t]{4}{*}{ Education } & Vocational school & 116 & 19.9 \\
\hline & First degree & 256 & 44.0 \\
\hline & Master degree & 139 & 23.9 \\
\hline & PhD degree & 71 & 12.2 \\
\hline \multirow[t]{2}{*}{ Marital Status } & Single or divorced & 179 & 43.8 \\
\hline & Married & 210 & 51.5 \\
\hline \multirow[t]{5}{*}{ Organizational Tenure } & $1-5$ years & 103 & 17.7 \\
\hline & $6-10$ years & 140 & 24.1 \\
\hline & $11-15$ years & 140 & 24.1 \\
\hline & $16-20$ years & 141 & 24.2 \\
\hline & More than 20 years & 58 & 10.0 \\
\hline \multirow[t]{5}{*}{ Children } & None & 127 & 21.8 \\
\hline & $1-2$ & 188 & 32.3 \\
\hline & $3-4$ & 218 & 37.5 \\
\hline & 5-6 & 45 & 7.7 \\
\hline & 7 and above & 4 & 0.7 \\
\hline
\end{tabular}

Source: Questionnaire Data, 2020.

\subsection{Measurement Model}

The outcomes of the measurement model are shown in Table 2. The convergent and discriminant validity of all items utilized in the research instrument is examined and interpreted. Outer loadings $(\lambda)$ of all observed items were above the threshold of 0.5 [42]. Rho_A values, composite reliability, and Cronbach's alpha were above the 0.7 thresholds [42]. The average variance extracted (AVE) recorded values above the 0.5 threshold, as recommended by Hair et al. (2015). These results confirmed the convergent validity of our measurement model. 
Table 2. Measurement model.

\begin{tabular}{|c|c|c|c|c|c|}
\hline Constructs and Indicators & Loadings $(\lambda)$ & Mean & Std. Deviation & Skewness & Kurtosis \\
\hline \multicolumn{6}{|l|}{ CSR Perception } \\
\hline CSRq01T1 & $0.906^{* * *}$ & 4.003 & 1.034 & -0.98 & 0.454 \\
\hline CSRq02T1 & $0.913^{* * *}$ & 4.268 & 0.906 & -1.11 & 0.458 \\
\hline CSRq03T1 & $0.898^{* * *}$ & 4.122 & 0.949 & -1.031 & 0.631 \\
\hline CSRq04T1 & $0.881^{* * *}$ & 4.131 & 0.942 & -0.87 & -0.086 \\
\hline CSRq05T1 & $0.901^{* * *}$ & 3.818 & 1.07 & -0.77 & 0.055 \\
\hline CSRq06T1 & $0.926^{* * *}$ & 4.132 & 0.962 & -0.929 & 0.071 \\
\hline CSRq07T1 & $0.814^{* * *}$ & 3.699 & 1.000 & -0.423 & -0.242 \\
\hline CSRq08T1 & $0.904^{* * *}$ & 4.101 & 1.066 & -1.219 & 0.888 \\
\hline CSRq09T1 & $0.819^{* * *}$ & 3.388 & 1.076 & -0.339 & -0.36 \\
\hline CSRq10T1 & $0.785^{* * *}$ & 3.024 & 1.144 & -0.006 & -0.741 \\
\hline CSRq11T1 & $0.779^{* * *}$ & 3.072 & 1.164 & -0.069 & -0.838 \\
\hline CSRq12T1 & $0.838^{* * *}$ & 3.854 & 1.149 & -0.87 & -0.04 \\
\hline CSRq13T1 & $0.910^{* * *}$ & 4.271 & 0.853 & -0.984 & 0.331 \\
\hline CSRq14T1 & $0.888^{* * *}$ & 4.234 & 0.858 & -0.894 & 0.135 \\
\hline CSRq15T1 & $0.868^{* * *}$ & 4.323 & 0.814 & -1.078 & 0.725 \\
\hline CSRq16T1 & $0.876^{* * *}$ & 4.198 & 0.891 & -0.851 & -0.071 \\
\hline CSRq17T1 & $0.900^{* * *}$ & 4.235 & 0.868 & -0.917 & 0.142 \\
\hline \multicolumn{6}{|c|}{ Organizational Identification (OI) } \\
\hline OIq1T1 & $0.976^{* * *}$ & 4.134 & 1.063 & -1.251 & 0.841 \\
\hline OIq2T1 & $0.947^{* * *}$ & 4.170 & 0.947 & -1.087 & 0.724 \\
\hline OIq3T1 & $0.984^{* * *}$ & 4.134 & 1.012 & -1.11 & 0.538 \\
\hline OIq4T1 & $0.969^{* * *}$ & 4.113 & 0.985 & -1.008 & 0.37 \\
\hline OIq5T1 & $0.969^{* * *}$ & 4.170 & 0.963 & -1.097 & 0.651 \\
\hline OIq6T1 & $0.968^{* * *}$ & 4.170 & 1.017 & -1.298 & 1.119 \\
\hline \multicolumn{6}{|l|}{ Employee Attachment (EA) } \\
\hline EAq1T1 & $0.951 * * *$ & 4.067 & 1.057 & -1.193 & 0.852 \\
\hline EAq2T1 & $0.934^{* * *}$ & 3.954 & 1.118 & -1.032 & 0.297 \\
\hline EAq3T1 & $0.888^{* * *}$ & 4.361 & 0.923 & -1.511 & 1.722 \\
\hline EAq4T1 & $0.944^{* * *}$ & 3.945 & 1.125 & -0.981 & 0.123 \\
\hline EAq5T1 & $0.957^{* * *}$ & 3.990 & 1.114 & -1.072 & 0.352 \\
\hline EAq6T1 & $0.889^{* * *}$ & 4.381 & 0.906 & -1.551 & 1.934 \\
\hline EAq7T1 & $0.862^{* * *}$ & 3.242 & 1.222 & -0.244 & -0.753 \\
\hline \multicolumn{6}{|c|}{ Employee Organizational Relationship (EOR) } \\
\hline EORq1T2 & $0.970 * * *$ & 5.108 & 1.598 & -0.97 & 0.287 \\
\hline EORq2T2 & $0.967^{* * *}$ & 5.093 & 1.604 & -0.943 & 0.218 \\
\hline EORq3T2 & $0.823 * * *$ & 3.708 & 1.742 & 0.029 & -0.732 \\
\hline EORq4T2 & $0.954^{* * *}$ & 5.009 & 1.646 & -0.906 & 0.126 \\
\hline EORq5T2 & $0.959^{* * *}$ & 5.009 & 1.661 & -0.914 & 0.112 \\
\hline EORq6T2 & $0.946^{* * *}$ & 4.950 & 1.653 & -0.779 & -0.1 \\
\hline EORq7T2 & $0.974^{* * *}$ & 5.119 & 1.640 & -1.033 & 0.343 \\
\hline EORq8T2 & $0.952^{* * *}$ & 5.012 & 1.651 & -0.889 & 0.052 \\
\hline EORq9T2 & $0.972^{* * *}$ & 5.156 & 1.636 & -1.068 & 0.444 \\
\hline EORq10T2 & $0.930^{* * *}$ & 5.153 & 1.819 & -1.154 & 0.29 \\
\hline EORq11T2 & $0.971^{* * *}$ & 5.067 & 1.655 & -0.955 & 0.087 \\
\hline EORq12T2 & $0.973^{* * *}$ & 5.067 & 1.646 & -0.949 & 0.114 \\
\hline EORq13T2 & $0.945^{* * *}$ & 5.076 & 1.885 & -1.081 & 0.014 \\
\hline EORq14T2 & $0.976^{* * *}$ & 5.246 & 1.670 & -1.125 & 0.389 \\
\hline EORq15T2 & $0.975^{* * *}$ & 5.232 & 1.676 & -1.109 & 0.339 \\
\hline EORq16T2 & $0.974^{* * *}$ & 5.261 & 1.702 & -1.135 & 0.358 \\
\hline EORq17T2 & $0.933^{* * *}$ & 5.241 & 1.743 & -1.137 & 0.285 \\
\hline EORq18T2 & $0.947^{* * *}$ & 5.387 & 2.062 & -1.181 & -0.045 \\
\hline EORq19T2 & $0.978^{* * *}$ & 5.380 & 1.944 & -1.223 & 0.18 \\
\hline EORq20T2 & $0.975^{* * *}$ & 5.363 & 1.938 & -1.215 & 0.168 \\
\hline
\end{tabular}


Table 2. Cont.

\begin{tabular}{|c|c|c|c|c|c|}
\hline Constructs and Indicators & Loadings $(\lambda)$ & Mean & Std. Deviation & Skewness & Kurtosis \\
\hline \multicolumn{6}{|l|}{ Extra Role Performance (ERP) } \\
\hline ERPq1T2 & $0.971^{* * *}$ & 4.227 & 0.918 & -1.24 & 1.345 \\
\hline ERPq2T2 & $0.967^{* * *}$ & 4.227 & 0.918 & -1.24 & 1.345 \\
\hline ERPq3T2 & $0.959^{* * *}$ & 4.216 & 0.926 & -1.198 & 1.172 \\
\hline ERPq4T2 & $0.920 * * *$ & 3.789 & 1.097 & -0.59 & -0.307 \\
\hline ERPq5T2 & $0.969^{* * *}$ & 4.237 & 0.919 & -1.26 & 1.378 \\
\hline ERPq6T2 & $0.967^{* * *}$ & 4.234 & 0.920 & -1.25 & 1.347 \\
\hline ERPq7T2 & $0.980^{* * *}$ & 4.220 & 0.945 & -1.162 & 0.913 \\
\hline ERPq8T2 & $0.985^{* * *}$ & 4.237 & 0.941 & -1.233 & 1.128 \\
\hline \multicolumn{6}{|l|}{ Corporate Reputation (CoRe) } \\
\hline CoReq1T2 & $0.993^{* * *}$ & 5.663 & 1.442 & -1.077 & 0.352 \\
\hline CoReq2T2 & 1.001 & 5.662 & 1.444 & -1.079 & 0.351 \\
\hline CoReq3T2 & $0.998^{* * *}$ & 5.651 & 1.449 & -1.055 & 0.286 \\
\hline
\end{tabular}

Note: ${ }^{* * *}=p<0.01$.

In ascertaining the discriminant validity, the Fornell-Larcker (1981) criterion was initially applied. This entailed the comparison of the inter-construct correlation values with the AVE square root for each of the constructs in the study [47]. As shown in Table 3, the square roots of AVE presented in bold font in the diagonal recorded higher results than the inter-construct relationship for each construct, with the exception of CSR and EA. For the CSR construct, we observe that the AVE square root is 0.872; however, its inter-construct correlations with EA, EOR, and OI are 0.933, 0.907, and 0.903, respectively. For the EA construct, the AVE square root is 0.919; however, its inter-construct correlations with CSR, EOR, and OI are 0.935, 0.927, and 0.960, respectively.

Table 3. Inter-construct correlations and convergent and discriminant validity.

\begin{tabular}{ccccccccccc}
\hline Constructs & CA & Rho & CR & AVE & CSR & CoRe & EA & EOR & ERP & OI \\
\hline CSR & 0.982 & 0.982 & 0.982 & 0.761 & $\mathbf{0 . 8 7 2}$ & 0.872 & 0.935 & 0.909 & 0.798 & 0.903 \\
CoRe & 0.998 & 0.998 & 0.998 & 0.995 & 0.872 & $\mathbf{0 . 9 9 7}$ & 0.863 & 0.896 & 0.807 & 0.833 \\
EA & 0.974 & 0.975 & 0.974 & 0.844 & 0.933 & 0.862 & $\mathbf{0 . 9 1 9}$ & 0.928 & 0.821 & 0.960 \\
EOR & 0.995 & 0.995 & 0.995 & 0.912 & 0.907 & 0.896 & 0.927 & $\mathbf{0 . 9 5 5}$ & 0.872 & 0.882 \\
ERP & 0.991 & 0.991 & 0.991 & 0.931 & 0.797 & 0.806 & 0.819 & 0.871 & $\mathbf{0 . 9 6 5}$ & 0.786 \\
OI & 0.989 & 0.989 & 0.989 & 0.939 & 0.903 & 0.833 & 0.960 & 0.882 & 0.786 & $\mathbf{0 . 9 6 9}$ \\
\hline
\end{tabular}

Notes: CA, Cronbach's Alpha; CR, composite reliability; Rho, Rho_A reliability indices; AVE, average variance extracted; diagonal values in bold are the square root of AVE; italicized values above the square root of AVE are Heterotrait-Monotrait (HTMT) ratios.

There has been harsh criticism of Fornell-Larcker's (1981) reliability in ascertaining discriminant validity, primarily when a partial least square methodology is used in estimating structural equation models [48]. Alternatively, the authors proposed the HeterotraitMonotrait (HTMT) method as a more vigorous procedure for determining discriminant validity when composite variables are involved [48]. After conducting a Monte-Carlo simulation, the authors indicated that the HTMT method is superior to the Fornell-Larcker (1981) criterion. HTMT test results were presented in italic font above the AVE square root in Table 3. In this study, the threshold of HTMT is $<1.0$, as recommended by Henseler et al. (2014). As observed in Table 3, on average, all constructs in the measurement model possess HTMT values $<1$, indicating discriminant validity among the constructs.

To assess collinearity, the variance inflation factor (VIF) is calculated for the independent construct. According to James et al., (2013), VIF values should be below the threshold of 10.0 [49]. Table 4 indicates the absence of collinearity and multi-collinearity between and among predictors. 
Table 4. Structural model multi-collinearity (VIF values).

\begin{tabular}{ccccccc}
\hline Construct & CSR & CoRe & EA & EOR & ERP & OI \\
\hline CSR Perception & - & 7.751 & 1 & 7.751 & 7.751 & 1 \\
\hline
\end{tabular}

\subsection{Assessing the Structural Model}

In order to assess the proposed relationships between variables presented in the conceptual framework in Figure $1, \mathrm{R}^{2}$ values, effect sizes $\left(\mathrm{f}^{2}\right)$, beta coefficients $(\beta)$, and $\mathrm{t}$-values obtained from bootstrapping, utilizing 2000 subsamples, were examined as recommended by Hair et al., (2015).

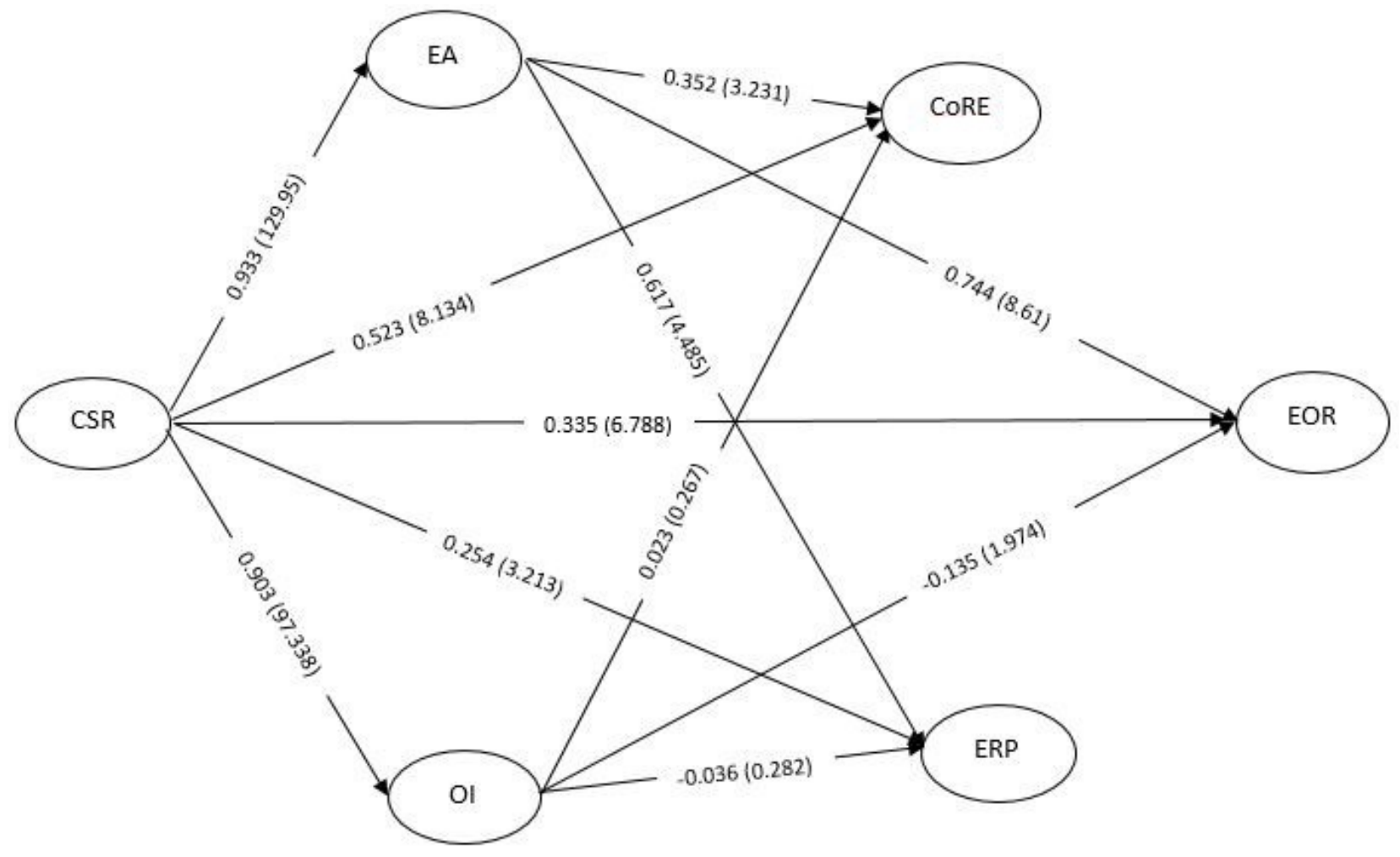

Figure 1. Structural model showing Beta Coefficients and $\mathrm{t}$ Statistics. Note: Brackets $=\mathrm{t}$ statistics.

The direct effect of independent variables on work outcome constructs were analyzed. From the results obtained, CSR perceptions had a positive and significant impact on EA $(\beta=0.933, p<0.05)$ and OI $(\beta=0.903, p<0.05)$, determining $87 \%\left(\mathrm{R}^{2}=0.87\right)$ and approximately $82 \%\left(\mathrm{R}^{2}=0.816\right)$ of its observed variance, respectively. CSR also positively and significantly influenced the outcome variables: CoRe $(\beta=0.523, p<0.05)$, EOR $(\beta=0.335, p<0.05)$, and ERP $(\beta=0.254, p<0.05)$. In addition, EA had a positive significant influence on CoRe $(\beta=0.352, p<0.05)$, EOR $(\beta=0.744, p<0.05)$, and ERP $(\beta=0.617$, $p<0.05)$. Meanwhile, OI was detected to have a negative yet significant relationship with $\operatorname{EOR}(\beta=-0.135, p<0.05)$, while its effect was not statistically significant on other outcome variables, namely: $\operatorname{CoRe}(\beta=0.023, p=0.789)$ and $\operatorname{ERP}(\beta=-0.036, p=0.778)$ respectively.

The indirect mediating effect of EA and OI between CSR and the outcome variables were also assessed and presented in Figure 1. EA significantly mediates the CSR-CoRe path $(\beta=0.328, t=3.224, p<0.05)$, CSR_EOR path $(\beta=0.694, t=8.476, p<0.05)$ and CSR-ERP path $(\beta=0.575, t=4.457, p<0.05)$. However, while OI significantly mediates the negative effect CSR has on EOR $(\beta=-0.122, t=1.967, p<0.05)$; its mediation effect on the CSR - CoRe path $(\beta=0.021, t=0.268, p>0.05)$ and the CSR-ERP path $(\beta=-0.032$, $t=0.281, p>0.05)$ are non-significant. Therefore, all direct paths hypothesized in the 
conceptual model are supported, with the exceptions of the path between OI and CoRe, as well as OI and ERP, while the majority of the indirect effects were significant, except for the following, CSR-OI-CoRe and CSR-OI-ERP.

In order to indicate the actual magnitude of observed effects, Sullivan and Feinn (2012) suggested reporting the effect sizes $\left(\mathrm{f}^{2}\right)$ [50]. The effect sizes of the direct and indirect paths are recorded in Table 5 . In this study, the effect sizes $\left(\mathrm{f}^{2}\right)$ were interpreted in accordance with Cohen (1988) [51]. For instance, $\mathrm{f}^{2}$ values equal to $0.02,0.15$, and 0.35 correspond to small, medium, and large effects, respectively. From Table 5, it becomes evident that two paths, CSR - EA and CSR - OI, recorded very large effect sizes; CSR - CoRe and five other paths shown in the table had large effects. Meanwhile, three paths, OI-EOR $\left(\mathrm{f}^{2}=0.011\right)$, $\mathrm{OI}-\mathrm{CoRe}\left(\mathrm{f}^{2}=0.000\right)$, and OI-ERP $\left(\mathrm{f}^{2}=0.000\right)$ fell below the threshold revealing negligible effect magnitudes as displayed by their $\mathrm{f}^{2}$ values. With regard to model fitness, the SRMR value was below the 0.08 threshold, indicating adequate model fit.

Table 5. Results of the path analysis.

\begin{tabular}{|c|c|c|c|c|c|c|}
\hline \multirow{2}{*}{$\begin{array}{c}\text { Hypotheses } \\
\text { Direct Effects }\end{array}$} & \multicolumn{6}{|c|}{ Model Fit Indices: SRMR = 0.029} \\
\hline & $B$ Values & $t$ Statistics & $p$-Values & $\mathrm{f}^{2}$ & $\mathbf{R}^{2}$ & Decision \\
\hline H1a: CSR-EA & 0.933 & 129.915 & 0.000 & 6.708 & 0.870 & Supported \\
\hline H1b: CSR-OI & 0.903 & 97.338 & 0.000 & 4.442 & 0.816 & Supported \\
\hline H2a: CSR-CoRe & 0.523 & 8.134 & 0.000 & 0.159 & 0.779 & Supported \\
\hline $\mathrm{H} 2 \mathrm{~b}: \mathrm{CSR}-\mathrm{EOR}$ & 0.335 & 6.788 & 0.000 & 0.115 & 0.875 & Supported \\
\hline H2c: CSR_ERP & 0.254 & 3.213 & 0.001 & 0.026 & 0.679 & Supported \\
\hline H3a: OI-CoRe & 0.023 & 0.267 & 0.789 & 0.000 & 0.779 & Not Supported \\
\hline H3b: OI-EOR & -0.135 & 1.974 & 0.049 & 0.011 & 0.875 & Supported \\
\hline H3c: OI-ERP & -0.036 & 0.282 & 0.778 & 0.000 & 0.679 & Not Supported \\
\hline H4a: EA-CoRe & 0.352 & 3.231 & 0.001 & 0.031 & 0.779 & Supported \\
\hline H4b: EA-EOR & 0.744 & 8.61 & 0.000 & 0.244 & 0.875 & Supported \\
\hline H4c: EA-ERP & 0.617 & 4.485 & 0.000 & 0.065 & 0.679 & Supported \\
\hline \multicolumn{7}{|c|}{ Indirect Effects } \\
\hline H5a: CSR-OI-CoRe & 0.021 & 0.268 & 0.789 & & & Not Supported \\
\hline H5b: CSR-OI-EOR & -0.122 & 1.967 & 0.049 & & & Supported \\
\hline H5c: CSR-OI-ERP & -0.032 & 0.281 & 0.778 & & & Not Supported \\
\hline H6a: CSR-EA-CoRe & 0.328 & 3.224 & 0.001 & & & Supported \\
\hline H6b: CSR-EA-EOR & 0.694 & 8.476 & 0.000 & & & Supported \\
\hline H6c: CSR-EA-ERP & 0.575 & 4.457 & 0.000 & & & Supported \\
\hline
\end{tabular}

The predictive validity of the conceptual model was examined according to Shmueli et al. (2016) recommendations utilizing PLS to predict the analysis via SmartPLS. Shmueli et al. (2016) suggested carrying out cross-validation using hold-out samples [52]. The $\mathrm{Q}^{2}$ values for each of the latent constructs are above zero, CoRe (0.745), EA (0.833), EOR (0.805), ERP (0.616), and OI (0.793); thus, indicating that the model has sufficient predictive validity. The error summary statistics, presented in Table 6, indicated that the root mean squared error (RMSE), mean absolute error (MAE), and mean absolute percentage error (MAPE) are all smaller (for most indicators) than those in the linear model (LM). However, a substantial number of indicators had their error summaries in the PLS model greater than those of the LM, indicating limited predictive power. Such a result can be interpreted in two ways; according to Shmueli et al., (2016), either the items assessing the constructs are insensitive to model changes, or the model aims to explain the items rather than predict them out-of-sample. However, in this model, the predictive relevance of the latent constructs contained in the model are more significant, thus ensuring its predictive validity. Therefore, it can be concluded that at the latent construct level, the predictive performance of the study model is sufficient. 
Table 6. PLS predict analysis.

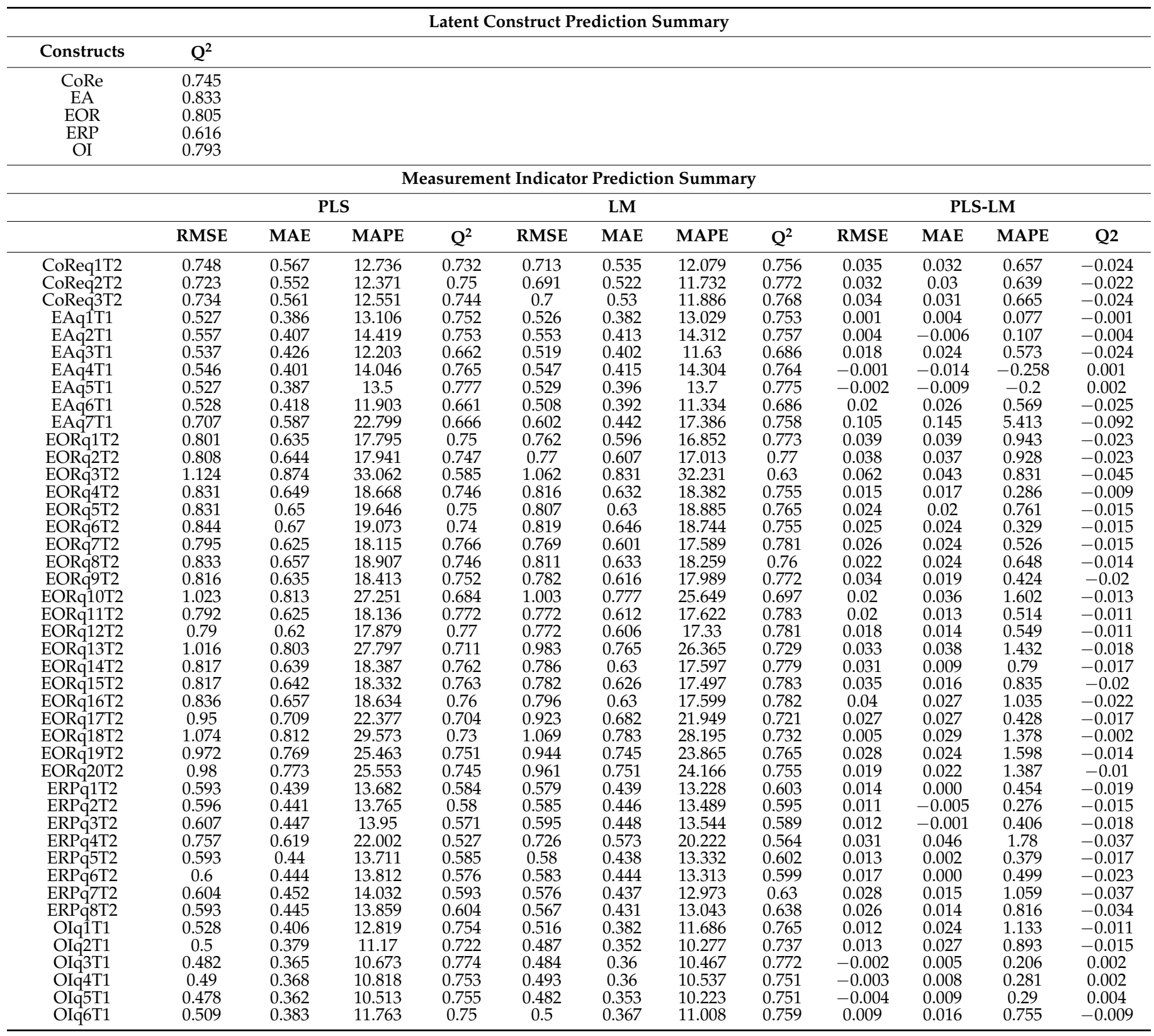

\section{Discussion and Conclusions}

\subsection{Summary of Results}

This study examines the interrelations among CSR and work outcomes, such as CoRe, EOR, and ERP mediated by EA and OI. The constructs mentioned above were developed in line with SET and SIT. This paper shows associations between the investigated variables using data collected from HCWs in Lebanese private hospitals.

Results show that CSR initiatives have a significant impact on EA and OI. This finding is consistent with SET, SIT, and other studies, revealing that firms integrating CSR initiatives enhance employees' OI [28] and strengthen their attachment to the workplace [6]. This finding also displays a notable connotation for practitioners and academics in the health care sector as the significant association between CSR and each of OI and EA [17,31].

As proposed, results show a substantial relationship between HCWs' CSR perceptions and valuable work outcomes as in CoRe, EOR, and ERP. This proclaims CSR as an essential tool promoting valuable work outcomes. The more the organization demonstrates fairness, 
the harder employees will work to improve CoRe. Recent empirical investigations support the positive impact of CSR on CoRe [7]. Furthermore, HCWs exhibit high commitment levels to their organizations, demonstrate satisfaction and trust, and recognize their authority and power to influence one another, thus developing a high-quality EOR. This is consistent with recent studies examining the impact of CSR activities on EOR [9]. Moreover, CSR influences employees' ERP positively, particularly in identifying with their socially responsible organization when reciprocating CSR activities in ERP $[8,13]$.

The study shows the significant impact of EA on each of CoRe, EOR, and ERP. This is in line with our findings from previous studies [17,36,37]. As employees demonstrate high levels of EA, they show higher satisfaction and more commitment. Furthermore, employees who positively perceive CSR initiatives are attached to their workplace, exerting a lot of effort in ERP to promote their organization's reputation. Contrary to our previous findings [13,14], there is no significant relationship between OI and each of CoRe and ERP. Previous studies specified that the health care sector in Lebanon faces a shortage of HCWs due to bad work conditions and work-life conflict that leads to an unstable workplace [53]. According to Skudiene and Auruskeviciene (2012), socially responsible firms which provide equitable wages, involve employees in decision-making, enhance honest and adaptable communication systems, and encourage personal and career development would foster beneficial work outcomes [54]. Conversely, the findings indicate a significant relationship between OI and EOR, particularly with employees who identify with their organization. As a result, they will feel more satisfied and demonstrate a high-quality EOR. These findings are consistent with recent studies inspecting the impact of OI on EOR [9].

Results indicate that EA acts as a mediator between employees' CSR perceptions and work outcomes; OI does not have a significant mediating role between CSR and each of CoRe and ERP. Hospitals that offer safe work conditions to their employees and enhance stakeholder well-being drive positive perceptions and improve reputations, EOR, and employees' ERP. This is evidently consistent with SIT, SET, and other studies [17,36]. Similarly, positive CSR perceptions increase employees' identification with their organizations, thus developing OI and a high quality of EOR. On the other hand, the mediating role of OI between CSR and each of CoRe and ERP is not supported [14,20]. Such result is inconsistent with the results of previous studies since the above mentioned relationships are highly affected by permanent exposure of HCWs to hazardous infections, patient aggression, huge time pressure associated with complex tasks, and heavy workload, adversely affecting HCWs' behavior [55].

\subsection{Theoretical Implications}

This research provides theoretical implications with insightful correlations between CSR, OI, EA, and HCWs' outcomes which are essential for the health care sector.

First, CSR describes the relationship between an organization and its community; yet, evidence is scarce on the impact of HCWs' CSR perceptions in the health care sector. Accordingly, it is imperative to examine the impact of employees' CSR perceptions in countries such as Lebanon, where CSR knowledge is overcast $[1,11,12]$.

Second, this study examined the impact of CSR on OI, EA, and work outcomes, selected based on relevant literature [13-15], as these associations have not yet been studied. Managers try to contribute ecologically to their communities while maintaining their organization's profitability [24]. The findings are consistent with previous research because positive perceptions of CSR enhance employees' identification [6,24] and improve work outcomes [7].

Third, studying the impact of EA and OI on work outcomes is essential $[15,56]$, especially in the health care sector. As HCWs act as their organization's spokesperson, they will enhance CoRe. Moreover, they will become engaged in high-quality EOR and ERP. Furthermore, the findings of this study provide additional theoretical and empirical support regarding the impact of OI on EOR [18]. Scarce empirical evidence in the literature [13,14] led to this study's examination of the interrelation of OI and EOR. However, the relation 
between OI and each of CoRe and ERP is not well-supported. Unlike in Lebanon, recent studies indicated a positive association between the variables mentioned above [13,14,29]. Therefore, this non-significant relation affirms that environment-related factors enable health care management to develop appropriate CSR strategies to meet the needs of HCWs.

Finally, the two mediating variables, OI and EA, thoroughly examined in this study, added further knowledge to the literature and revealed new outcomes of CSR in the health care sector. Previous studies indicated OI as a mediator; however, this study is the first to demonstrate that OI does not mediate the relationship between CSR and each of CoRe and ERP.

\subsection{Practical Implications}

Findings regarding the interrelationship of the investigated variables reveal significant managerial implications.

First, based on the results of Hypotheses 1 and 2, which indicate the positive impact of employees' CSR perceptions on OI, EA, and other work outcomes as CoRe, EOR, and ERP, top managers should reconsider CSR initiatives that appeal to employees' needs and desires while formulating and implementing CSR strategies.

Second, results show that EA significantly impacts CoRe, EOR, and ERP, unlike OI, which has no significant impact on CoRe and ERP. Therefore, managers must consider the different backgrounds of HCWs when designing and implementing CSR strategies. Moreover, managers should conduct internal marketing assessments regularly to determine the needs, values, and desires of HCWs while planning the organization's CSR strategies.

Third, results also indicate that the mediating role of OI between CSR and each of CoRe and ERP is not significant in the Lebanese health care sector. These findings drive managers to carefully determine which particular CSR initiatives are essential for different levels of HCWs. To accomplish this goal, managers should trigger employees awareness of CSR initiatives after providing them with sufficient information related to CSR programs and engaging them in the CSR decision-making process to enhance work outcomes. Moreover, this study inspires human resource management to integrate CSR strategies in human resource management practices. Hospitals' top management and policymakers can restructure their strategic plans by incorporating long-term CSR policies and developing their core value based on social responsibility. For instance, it is essential for hospitals to hire workers who exhibit similar values.

Fourth, since results show that the mediating role of OI on the relationship between CSR and each of CoRe and ERP is insignificant in addition to its significant yet negative impact on the CSR-EOR pathway, marketers should utilize CSR as a powerful marketing tool to improve work outcomes through increasing employees' OI; thus, introducing new CSR research paradigms. Marketers should realize that the organization's CSR communication affects employees' CSR perceptions. Therefore, it would be meaningful to integrate effective communication channels to trigger $\mathrm{HCWs}^{\prime}$ awareness regarding the ongoing CSR initiatives.

Finally, based on the results of the mediating EA role and on previous literature indicating that Lebanon's health care suffers from an HCW shortage (due to inadequate working conditions and bad working experiences [53]), implementation of CSR initiatives will assist hospitals to develop a positive image and an attractive profile for HCWs.

\subsection{Limitations and Future Research Suggestions}

This research contributes to the literature by examining the interrelationships of CSR, OI, EA, CoRe, EOR, and ERP. However, potential drawbacks and future research suggestions are identified.

First, this study adopts Turker's scale (2009) to assess HCWs' CSR perceptions. Turker's scale does not permit the researcher to determine which CSR activities strongly impact employees' perceptions. Assessing the four dimensions of CSR [57], as identified 
in Carroll's model (1991), can add further understanding regarding the impact of CSR implementation in the health care sector.

Second, unlike OI, EA seems to mediate the relationship between CSR and work outcomes, which strictly mediates the relationship between CSR and EOR. Future research may investigate other mediators or moderators such as social media, patient aggression, workload, work-life balance satisfaction, and cultural fit between organizations' culture and CSR activities.

Third, the study's relationships were tested via a sample of HCWs in Lebanon, with a two-week interval, in two waves, in a cross-sectional design. Therefore, the causality between the study's constructs could not be precisely established. To overcome the limitations of cross-sectional data, longitudinal research is suggested.

Fourth, since the results are not as strong as expected for the scope of the research, researchers can adapt both qualitative and quantitative approaches to provide a more in-depth understanding of the results. Moreover, this study was conducted only in the health care sector, which limits the interpretation of the relationship among constructs. Therefore, more experimental examinations should be conducted to clarify the relationships highlighted in this paper.

Fifth, regarding the data collection process, the supervisors assisted the researchers in gathering the surveys from employees in various departments within private hospitals. To prevent the risk of selection bias in future studies, researchers should collect data directly from HCWs. Moreover, self-reported data include personal biases depending on participant likes and dislikes. To overcome this limitation, future studies should use human-to-system modern processes to assess employee CSR perceptions in health care settings. Lastly, the findings of the study can be replicated in developed countries with larger sample sizes and in other sectors (e.g., airline, banking).

Supplementary Materials: The following are available online at https:/ /www.mdpi.com/article/10 .3390/su13179840/s1, Questionnaire 1 and 2: A Field Study in The Healthcare Sector of Lebanon.

Author Contributions: Conceptualization, S.H. and G.K.; methodology, S.H. and G.K.; software, O.L.E.; writing—original draft preparation, S.H.; writing—review and editing, G.K.; supervision, G.K. All authors have read and agreed to the published version of the manuscript.

Funding: This research received no external funding.

Institutional Review Board Statement: All procedures performed in this study involving data collection were in accordance with the ethical standards of the participating hospitals.

Informed Consent Statement: Informed consent was obtained from all individual participants included in this study.

Data Availability Statement: The data generated and analyzed during the current study are available from the corresponding author on reasonable request.

Acknowledgments: In this research, we are grateful for the assistance of anonymous reviewers and the editors for their invaluable comments to improve this paper.

Conflicts of Interest: The authors declare no conflict of interest.

\section{References}

1. Hossain, M.S.; Yahya, S.B.; Khan, M.J. The effect of corporate social responsibility (CSR) health-care services on patients' satisfaction and loyalty-A case of Bangladesh. Soc. Responsib. J. 2019, 16, 145-158. [CrossRef]

2. Khalife, J.; Rafeh, N.; Makouk, J.; El-Jardali, F.; Ekman, B.; Kronfol, N.; Hamadeh, G.; Ammar, W. Hospital contracting reforms: The Lebanese Ministry of Public Health experience. Health Syst. Reform. 2017, 3, 34-41. [CrossRef]

3. Gond, J.P.; El Akremi, A.; Swaen, V.; Babu, N. The psychological microfoundations of corporate social responsibility: A personcentric systematic review. J. Organ. Behav. 2017, 38, 225-246. [CrossRef]

4. Asante Boadi, E.; He, Z.; Bosompem, J.; Opata, C.N.; Boadi, E.K. Employees' perception of corporate social responsibility (CSR) and its effects on internal outcomes. Serv. Ind. J. 2020, 40, 611-632. [CrossRef]

5. Frazier, M.L.; Gooty, J; Little, L.M.; Nelson, D.L. Employee attachment: Implications for supervisor trustworthiness and trust. J. Bus. Psychol. 2015, 30, 373-386. [CrossRef] 
6. Luke, M.A.; Carnelley, K.B.; Sedikides, C. Attachments in the workplace: How attachment security in the workplace benefits the organisation. Eur. J. Soc. Psychol. 2020, 50, 1046-1064. [CrossRef]

7. Benitez, J.; Ruiz, L.; Castillo, A.; Llorens, J. How corporate social responsibility activities influence employer reputation: The role of social media capability. Decis. Support Syst. 2020, 129, 113223. [CrossRef]

8. Farooq, O.; Rupp, D.E.; Farooq, M. The multiple pathways through which internal and external corporate social responsibility influence organizational identification and multifoci outcomes: The moderating role of cultural and social orientations. Acad. Manag. J. 2017, 60, 954-985. [CrossRef]

9. Chen, Z.; Hong, C.; Occa, A. How different CSR dimensions impact organization-employee relationships. Corp. Commun. Int. J. 2019, 24, 63-78. [CrossRef]

10. Al-Abdin, A.; Roy, T.; Nicholson, J. Researching Corporate Social Responsibility in the Middle East: The Current State and Future Directions. Corp. Soc. Responsib. Environ. Manag. 2017, 25, 47-65. [CrossRef]

11. Jamali, D.; Karam, C. Corporate social responsibility in developing countries as an emerging field of study: CSR in developing countries. Int. J. Manag. Rev. 2018, 20, 32-61. [CrossRef]

12. Amos, G.J. Researching corporate social responsibility in developing-countries context: A systematic review of the literature. Int. J. Law Manag. 2018, 60, 284-310. [CrossRef]

13. John, A.; Qadeer, F.; Shahzadi, G.; Jia, F. Corporate social responsibility and employee's desire: A social influence perspective. Serv. Ind. J. 2017, 37, 819-832. [CrossRef]

14. John, A.; Qadeer, F.; Shahzadi, G.; Jia, F. Getting paid to be good: How and when employees respond to corporate social responsibility? J. Clean. Prod. 2019, 215, 784-795. [CrossRef]

15. Gemmel, P.; Verleye, K. Emotional Attachment to a Hospital: Brining Employees and Customers into the Engagement Zone. J. Appl. Manag. Entrep. 2010, 15, 78-93.

16. Yadav, R.S.; Dash, S.S.; Chakraborty, S.; Kumar, M. Perceived CSR and corporate reputation: The mediating role of employee trust. Vikalpa 2018, 43, 139-151. [CrossRef]

17. Kim, H.L.; Rhou, Y.; Uysal, M.; Kwon, N. An examination of the links between corporate social responsibility (CSR) and its internal consequences. Int. J. Hosp. Manag. 2017, 61, 26-34. [CrossRef]

18. Story, J.S.P.; Castanheira, F. Corporate social responsibility and employee performance: Mediation role of job satisfaction and affective commitment. Corp. Soc. Responsib. Environ. Manag. 2019, 26, 1361-1370. [CrossRef]

19. Donia, M.B.L.; Ronen, S.; Tetrault Sirsly, C.A.; Bonaccio, S. CSR by any other name? The differential impact of substantive and symbolic CSR attributions on employee outcomes. J. Bus. Ethics 2019, 157, 503-523. [CrossRef]

20. Almeida, M.G.C.; Coelho, A.F.M. The antecedents of corporate reputation and image and their impacts on employee commitment and performance: The moderating role of CSR. Corp. Reput. Rev. 2019, 22, 10-25. [CrossRef]

21. Slack, R.E.; Corlett, S.; Morris, R. Exploring employee engagement with (corporate) social responsibility: A social exchange perspective on organizational participation. J. Bus. Ethics 2015, 127, 537-548. [CrossRef]

22. Gürlek, M.; Tuna, M. Corporate social responsibility and work engagement: Evidence from the hotel industry. Tour. Manag. Perspect. 2019, 31, 195-208. [CrossRef]

23. Jones, D.A. Does serving the community also serve the company? Using organizational identification and social exchange theories to understand employee responses to a volunteerism programme. J. Occup. Organ. Psychol. 2010, 83, 857-878. [CrossRef]

24. Farooq, M.S.; Salam, M. Nexus between CSR and DSIW: A PLS-SEM approach. Int. J. Hosp. Manag. 2020, 86, 102437. [CrossRef]

25. Brieger, S.A.; Anderer, S.; Fröhlich, A.; Bäro, A.; Meynhardt, T. Too much of a good thing? On the relationship between CSR and employee work addiction. J. Bus. Ethics 2019, 166, 311-329. [CrossRef]

26. Brammer, S.; Millington, A.; Rayton, B. The contribution of corporate social responsibility to organizational commitment. Int. J. Hum. Resour. Manag. 2007, 18, 1701-1719. [CrossRef]

27. Mael, F.; Ashforth, B.E. Alumni and their alma mater: A partial test of the reformulated model of organizational identification. J. Organ. Behav. 1992, 13, 103-123. [CrossRef]

28. Fatma, M.; Khan, I.; Rahman, Z. CSR and consumer behavioral responses: The role of customer-company identification. Asia Pac. J. Mark. Logist. 2018, 30, 460-477. [CrossRef]

29. Tufan, P.; Wendt, H. Organizational identification as a mediator for the effects of psychological contract breaches on organizational citizenship behavior: Insights from the perspective of ethnic minority employees. Eur. Manag. J. 2020, 38, 179-190. [CrossRef]

30. Ainsworth, M.; Blehar, M.; Waters, E.; Wall, S. Patterns of Attachment. A Psychological Study of the Strange Situation; Lawrence Erlbaum: Hillsdale, NJ, USA, 1978.

31. Rioux, L.; Pignault, A. Workplace attachment, workspace appropriation, and job satisfaction. Psyecology 2013, 4, 39-65. [CrossRef]

32. Hon, L.; Grunig, J. Guidelines for Measuring Relationships in Public Relations. Institute for Public Relations Website. 1999. Available online: http://www.instituteforpr.org/index.php/IPR/research_single/guidelines_measuring_relationships/ (accessed on 12 December 2019).

33. Farid, T.; Iqbal, S.; Ma, J.; Castro-González, S.; Khattak, A.; Khan, M.K. Employees' perceptions of CSR, work engagement, and organizational citizenship behavior: The mediating effects of organizational justice. Int. J. Environ. Res. Public Health 2019, 16, 1731. [CrossRef]

34. Crawshaw, J.R.; Game, A. The role of line managers in employee career management: An attachment theory perspective. Int. J. Hum. Resour. Manag. 2015, 26, 1182-1203. [CrossRef] 
35. Le Roy, J.; Rioux, L. The mediating role of work place attachment in the relationship between organizational commitment and organizational citizenship behavior. Rev. Int. Psychol. Soc. 2013, 3, 211-233.

36. Scrima, F.; Di Stefano, G.; Guarnaccia, C.; Lorito, L. The impact of adult attachment style on organizational commitment and adult attachment in the workplace. Pers. Individ. Dif. 2015, 86, 432-437. [CrossRef]

37. Rioux, L. Comfort at work: An indicator of quality of life at work. In Handbook of Environmental Psychology and Quality of Life Research; Springer International Publishing: Cham, Switzerland, 2017; pp. 401-419.

38. Carmeli, A.; Gilat, G.; Waldman, D.A. The role of perceived organizational performance in organizational identification, adjustment and job performance. J. Manag. Stud. 2007, 44, 972-992. [CrossRef]

39. Brammer, S.; He, H.; Mellahi, K. Corporate Social Responsibility, Employee Organizational Identification, and Creative Effort. Group Organ. Manag. 2015, 40, 323-352. [CrossRef]

40. Cheema, S.; Afsar, B.; Javed, F. Employees' corporate social responsibility perceptions and organizational citizenship behaviors for the environment: The mediating roles of organizational identification and environmental orientation fit. Corp. Soc. Responsib. Environ. Manag. 2019, 27, 9-21. [CrossRef]

41. Podsakoff, P.M.; MacKenzie, S.B.; Podsakoff, N.P. Sources of method bias in social science research and recommendations on how to control it. Annu. Rev. Psychol. 2012, 63, 539-569. [CrossRef] [PubMed]

42. Hair, J.; Hult, G.T.M.; Ringle, C.M.; Sarstedt, M. A Primer on Partial Least Squares Structural Equation Modeling (PLS-SEM), 2nd ed.; SAGE Publications: Los Angeles, CA, USA, 2015.

43. Turker, D. How corporate social responsibility influences organizational commitment. J. Bus. Ethics 2009, 89, 189-204. [CrossRef]

44. Rioux, L. Construction d'une échelle d'attachement au lieu de travail: Une démarche exploratoire. Can. J. Behav. Sci. 2006, 38, 325-336. [CrossRef]

45. Eisenberger, R.; Karagonlar, G.; Stinglhamber, F.; Neves, P.; Becker, T.E.; Gonzalez-Morales, M.G.; Steiger-Mueller, M. Leadermember exchange and affective organizational commitment: The contribution of supervisor's organizational embodiment. J. Appl. Psychol. 2010, 95, 1085-1103. [CrossRef]

46. Lai, C.S.; Chiu, C.J.; Yang, C.F.; Pai, D.C. The effects of corporate social responsibility on brand performance: The mediating effect of industrial brand equity and corporate reputation. J. Bus. Ethics 2010, 95, 457-469. [CrossRef]

47. Fornell, C.; Larcker, D.F. Evaluating structural equation models with unobservable variables and measurement error. J. Mark. Res. 1981, 18, 39-50. [CrossRef]

48. Henseler, J.; Ringle, C.M.; Sarstedt, M. A new criterion for assessing discriminant validity in variance-based structural equation modeling. J. Acad. Mark. Sci. 2014, 43, 115-135. [CrossRef]

49. James, G.; Witten, D.; Hastie, T. An Introduction to Statistical Learning: With Applications in R; Springer: New York, NY, USA, 2013.

50. Sullivan, G.M.; Feinn, R. Using effect size-or why the P value is not enough. J. Grad. Med. Educ. 2012, 4, 279-282. [CrossRef]

51. Cohen, J. Statistical Power Analysis for the Behavioral Sciences; L. Erlbaum Associates: Hillsdale, NJ, USA, 1988.

52. Shmueli, G.; Ray, S.; Velasquez Estrada, J.M.; Chatla, S.B. The elephant in the room: Predictive performance of PLS models. J. Bus. Res. 2016, 69, 4552-4564. [CrossRef]

53. Alameddine, M.; Kharroubi, S.; Dumit, N.; Kassas, S.; Diab-El-Harake, M.; Richa, N. What made Lebanese emigrant nurses leave and what would bring them back? A cross-sectional survey. Int. J. Nurs. Stud. 2020, 103, 103497. [CrossRef]

54. Skudiene, V.; Auruskeviciene, V. The contribution of corporate social responsibility to internal employee motivation. Balt. J. Manag. 2012, 7, 49-67. [CrossRef]

55. Lederer, W.; Paal, P.; Von Langen, D.; Sanwald, A.; Traweger, C.; Kinzl, J.F. Consolidation of working hours and work-life balance in anaesthesiologists-A cross-sectional national survey. PLoS ONE 2018, 13, e0206050. [CrossRef]

56. Vallaster, C. Managing a company crisis through strategic corporate social responsibility: A practice-based analysis: Strategic CSR as a way out of a company crisis. Corp. Soc. Responsib. Environ. Manag. 2017, 24, 509-523. [CrossRef]

57. Carroll, A. The pyramid of corporate social responsibility: Toward the moral management of organizational stakeholders. Bus. Horiz. 1991, 34, 39-48. [CrossRef] 